KARIN MARIANNE THIERS HERNÁNDEZ

ÁREA DISEÑO Y COMUNICACIÓN

UNIVERSIDAD TECNOLÓGICA DE CHILE INACAP

VALPARAÍSO, CHILE

KARIN.THIERS@INACAPMAIL.CL

FABIO EDUARDO ARES

FACULTAD DE BELLAS ARTES

UNIVERSIDAD NACIONAL DE LA PLATA

LA PLATA, ARGENTINA

DIRECCIÓN GENERAL PATRIMONIO, MUSEOS Y

CASCO HISTÓRICO DEL GOBIERNO DE LA CIUDAD

DE BUENOS AIRES

BUENOS AIRES, ARGENTINA

FABIOARES_DCV@YAHOO.COM.AR

\section{Letras urbanas históricas de Valparaíso. Estudio, rescate y puesta en valor patrimonial}

\author{
Historical urban letters of Valparaíso. \\ Study, rescue and enhancement of heritage value
}

Resumen. Valpo. Ciudad de Letras es un proyecto que pretende estudiar y poner en valor las letras históricas que se encuentran en las zonas patrimoniales de Valparaíso, Chile. Este aspecto constituye un enfoque novedoso sobre el patrimonio porteño. Conocer y recuperar sus letras históricas también es rescatar una parte importante de las actuaciones sociales, políticas y económicas de sus habitantes, sus representaciones e identidad visual. Este artículo se concentrará fundamentalmente en la metodología propuesta para el trabajo de campo que servirá de base para el análisis de los usos letragráficos de dicha ciudad, pero también propondrá algunas acciones tendientes a integrar la letra a su paisaje cultural.

Palabras clave: historia, letras, patrimonio, rotulación, Valparaíso.

\begin{abstract}
Valpo. City of Letters is a project that aims to study and value the historical letters of the heritage areas of Valparaíso, Chile. This aspect constitutes a novel approach to the patrimony of the city. Knowing and recovering its historical letters is also rescuing an important part of the social, political and economic actions of its inhabitants, their representations and visual identity. This article will focus mainly on the methodology proposed for the fieldwork that will serve as the basis for the analysis of lettering uses of a city, but will also propose some actions tending to integrate the letter to the cultural landscape.
\end{abstract}

Keywords: heritage, history, letters, rotulation, Valparaíso.

Fecha de recepción: 04/07/2018

Fecha de aceptación: 25/09/2018

Cómo citar: Thiers Hernández, K. y Ares, F.

(2018) Letras urbanas históricas de Valparaíso.

Estudio, rescate y puesta en valor patrimonial.

RChD: creación y pensamiento, 3(5), 1-12

DOI: 10.5354/0719-837X.2018.49741

Revista Chilena de Diseño,

RChD: creación y pensamiento

Universidad de Chile

2018, 3(5)

http://rchd.uchile.cl 
1. Zona Típica (1971), Sitio del Patrimonio Mundial (UNESCO, 2003) y barrio El Almendral.

2. Farias, Silva Gouveia, Pereira, Gallo, \& Gatto

(2008) llaman de esta manera a la letra que es producto de expresiones populares «no oficiales» como es el caso del grafitti.

\section{Introducción}

Desde fines del año 2015, se desarrolló un trabajo de investigación que tiene como objeto de estudio las letras utilizadas dentro de las áreas patrimoniales $^{1}$ de la ciudad de Valparaíso (Chile), para la identificación de organismos públicos y privados, cartelería comercial, nomenclatura, equipamiento urbano e incluso transporte.

El proyecto denominado Valpo. Ciudad de Letras constituye un enfoque novedoso sobre el patrimonio porteño relevante para el estudio y la revalorización de parte de la historia de los usos letragráficos chilenos, su patrimonio e identidad visual.

Según nuestro criterio, conocer estos usos en la rotulación urbana sería conocer buena parte de las actuaciones y formas de organización de esa comunidad a lo largo de la historia. En concordancia con David Hernández (2014: p. 20), es un "sistema significativo en el complejo de las relaciones sociales".

Para ello, primero es necesario ubicar casos relevantes dentro de las áreas patrimonialmente protegidas; y registrarlos para analizarlos y luego ponerlos en valor, a través de acciones de difusión, restauración, rescate, entre otros.

A diferencia de lo que sucedió con la investigación sobre tipografía para obras, el uso de letras en el entorno fue -y es aún en la actualidad- muy poco estudiado en el mundo, y menos aún en Latinoamérica. Recién a partir de la década de los años setenta del siglo XX, se comenzaron a editar algunos trabajos sobre este tema. La mayoría de estos asocian la letra a la arquitectura (tanto las aplicaciones permanentes como eventuales) y, como lo afirmó la tipógrafa Angelina Sánchez (2014), suscriben a la idea de los edificios "hablantes".

En concordancia con las investigadoras brasileras Silva Gouveia, Farias y Souza Gatto, quienes desde hace varios años se destacan en la indagación de la rotulación de San Pablo, Brasil, observamos la ciudad a través de una mirada amplia y estructural que incluye el "paisaje tipográfico" (2009: p. 339).

Priscila Lena Farias cita con frecuencia los aportes conceptuales y metodológicos del arquitecto Kevin Lynch, especialmente en la obra The Image of the City (1960), quien al parecer fue el que introdujo la idea de "leer" el ambiente urbano a través de los elementos visuales que lo componen, en una propuesta muy vinculada a la percepción y en la cual la letra es un elemento importante, aunque no es el único.

Dentro de esta concepción, al ambiente público construido determinado por la arquitectura, se le agrega el diseño de la información. De esta manera estructuran su libro Phil Baines y Catherine Dixon (2004), quienes marcan una fuerte división entre "letras en señales para dirigir e informar" y "letras para nombrar lugares y definir espacios".

Sabemos que los investigadores deben necesariamente generar modelos de clasificación para organizar el producto de sus estudios, y en ese sentido proponen diferentes planos para el análisis de lo registrado.

La mayoría se articula a partir de su función dentro del mensaje que integra, y se completa con aspectos tan variados como su estilo, su capacidad simbólica o su materialidad. Una tipografía puede identificar un edificio y decir qué empresa u organización funciona dentro de sus paredes; ordenar la circulación a través de las señales, la nomenclatura o la numeración domiciliaria; ayudar a comercializar un determinado producto; conmemorar un acontecimiento del pasado u homenajear a un prócer; o simplemente decorar un espacio valiéndose de sus capacidades expresivas, aún de forma "accidental”. 

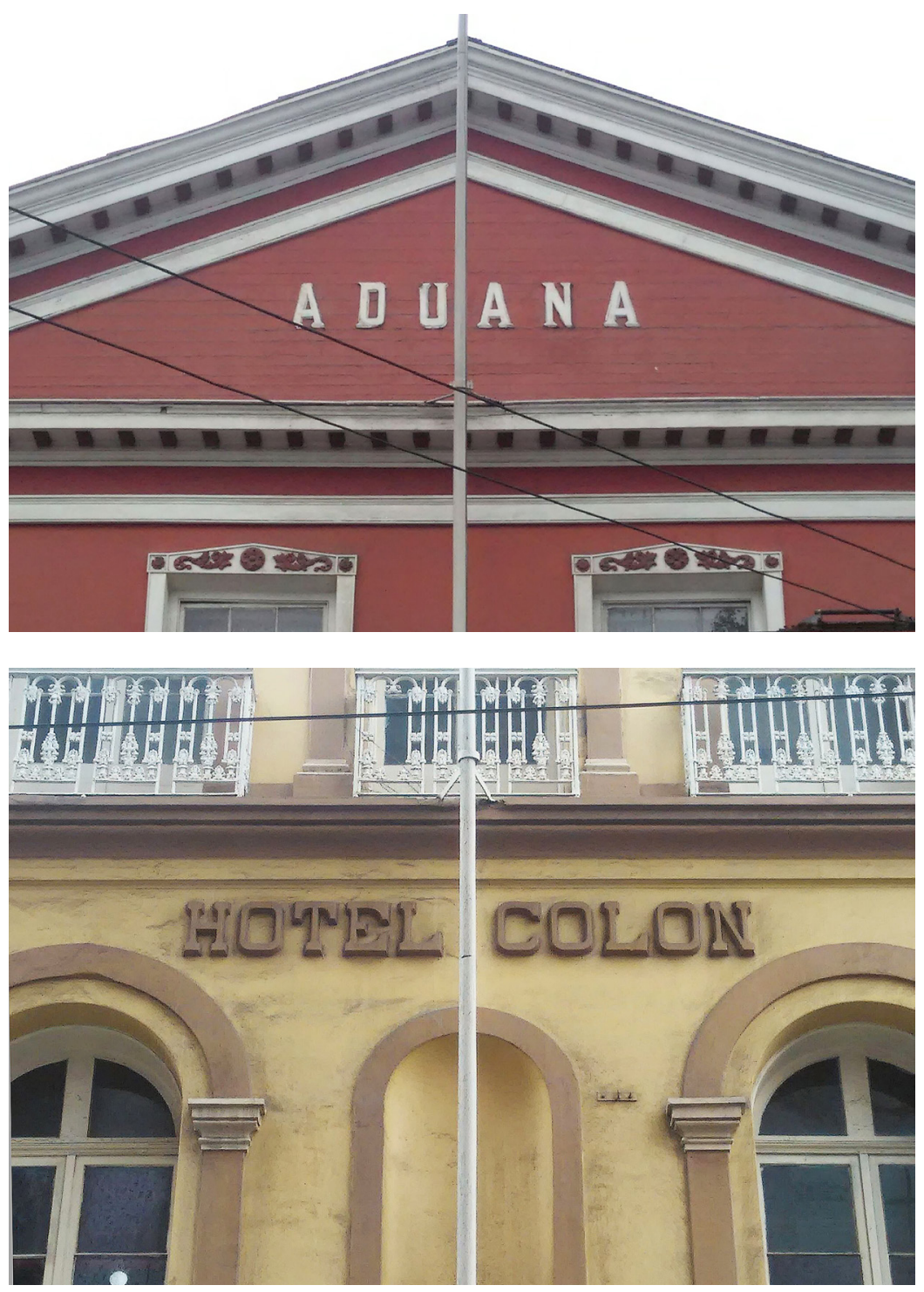

La profesora argentina Silvia H. González (2014) sostuvo que la función de la letra -al menos para el caso de las inscripciones arquitectónicas utilitarias o decorativas - está condicionada por factores de diversa índole, tales como el ambiente, las características del sitio de emplazamiento, las tecnologías y la escala.

\section{Propuesta metodológica}

Entendemos a la letra histórica de Valparaíso como el registro textual de las actuaciones políticas, económicas, tecnológicas y sociales de la comunidad porteña. Como señalara el doctor en Bellas Artes, Ricard Huerta (2013: p. 133), acerca de recorrer las letras de una ciudad, "conocer la ciudad, preferentemente caminando y fotografiando, significa rastrear su historia, sus deficiencias, sus particularidades, sus novedades".
Figura 1. Letras identificatorias sobre el frontis de la Aduana de Valparaíso. Hasta 1912, se ubicaban unos metros más abajo. Luego fueron colocadas en ese lugar de la fachada. Fuente: elaboración propia. Figura 2. Letras egipcias en el Hotel Colón, cuyo edificio fue construido en 1864 y soportó el terremoto de 1906. Fuente: elaboración propia. 
Figura 3. Letras conmemorativas en el Cementerio $n^{\circ} 1$. Fuente: elaboración propia.

3. Se recomienda consultar el trabajo que el autor se encuentra realizando junto con el colega diseñador Octavio Osores, sobre la tipografía histórica de los ferrocarriles argentinos.

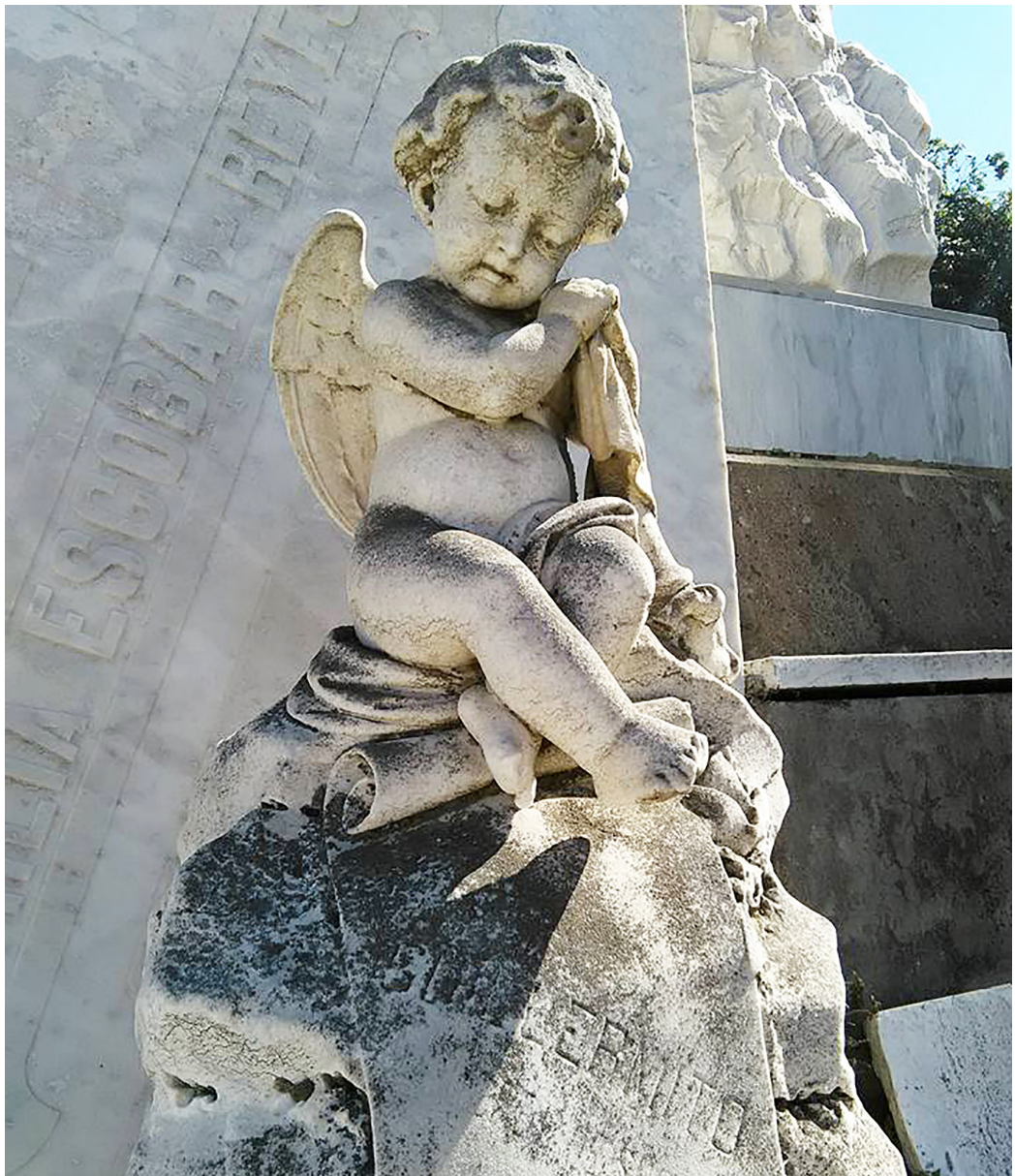

Asimismo, las paulistas Laura González Díez y María Tabuenca Bengoa (2015: p. 29), señalaron:

La rotulación y la tipografía plasmada a pie de calle es capaz de conferir una identidad propia a cualquier entorno urbano, ya sea en la calle, plaza o barrio. Las calles se erigen en verdaderos escaparates de la vida ciudadana y son un reflejo de la vitalidad de las urbes. $Y$ en ellas, los rótulos desempeñan un papel esencial porque la hacen más comprensible y accesible a quienes la viven y visitan.

Es una forma de comunicación y expresión que trasciende las fachadas y abarca a la ciudad toda, que incluye las letras que se encuentran en movimiento, por ejemplo, las que se incorporan a los transportes ${ }^{3}$, o incluso a la indumentaria de los habitantes, lo que transforma a cada uno en una suerte de "letrero andante" (Huerta, 2017: p. 9).

Como espacio temporal, tomaremos desde las últimas décadas de siglo XIX (los años de mayor esplendor del puerto) hasta el fin de siglo XX (momento en que se reconoció a la ciudad como patrimonio de la humanidad). Es muy importante indagar el contexto que rodeó estas prácticas, conocer los aspectos de cada momento histórico, relacionarlos con la tipografía, y de 


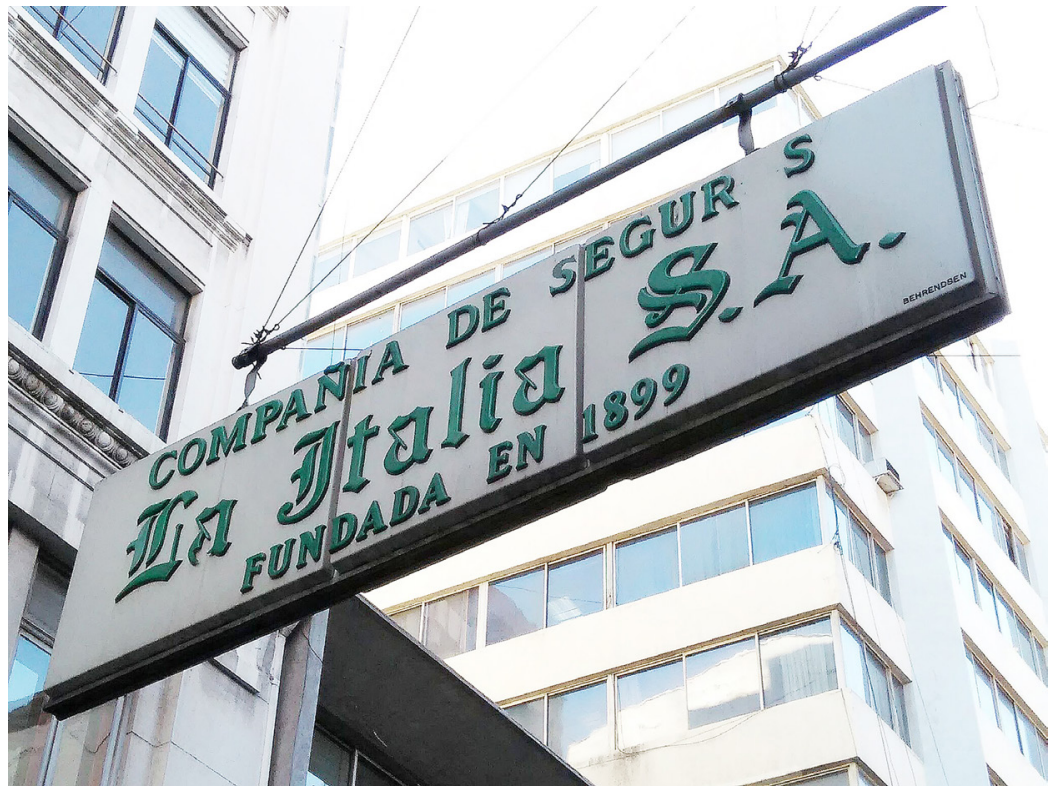

esta forma construir un marco referencial pertinente. Marina Garone Gravier (2004: p. 51), investigadora de la tipografía y de la cultura visual en Latinoamérica, dijo al respecto:

(...) en América Latina hay mucho por investigar e historiar en el ámbito tipográfico (...) si no asumimos el reto nos seguiremos encontrando con textos foráneos, pobremente documentados, y naturalmente deficientes en su entendimiento de nuestra realidad histórica y cultural.

Esta mirada integral necesita de taxonomías amplias. Al final de la investigación, la lectura relacional de los tópicos que la conforman permitirá responder interrogantes como: ¿por qué se encuentran allí?, ¿ dónde se ubicaron?, ¿quiénes las generaron?, ¿de qué manera?, ¿de dónde vinieron? Estas fueron algunas de las preguntas que obligaron a proponer una clasificación lo suficientemente amplia como para ordenar el trabajo de campo. Una propuesta personal para abordar el estudio de la letra en el entorno.

\section{Criterios para el registro de letras patrimoniales}

En nuestro proyecto, cada letra que sea individualizada durante el relevamiento -algunos parámetros propios de la comunicación visual, la rotulación y la disciplina tipográfica- será registrada con atención a los siguientes aspectos:

- Función dentro del mensaje visual: las letras no se encuentran allí por casualidad, poseen funciones muy específicas dentro de los mensajes visuales emitidos por las organizaciones públicas y privadas. Estas fueron incorporadas para la identificación corporativa, la señalización, la indicación de lugares o situaciones, la información y hasta la decoración de algunos sitios. Tomaremos las funciones identificativa, expresiva, persuasiva, informativa, estética, fática, conmemorativa y metalingüística.
Figura 4. Letrero de acrílico fabricado por la firma Behrendsen. Fuente: elaboración propia. 
Figura 5. Letras geométricas caladas sobre soporte de chapa. Mercado El Cardonal en Valparaíso, Chile. Fuente: elaboración propia.

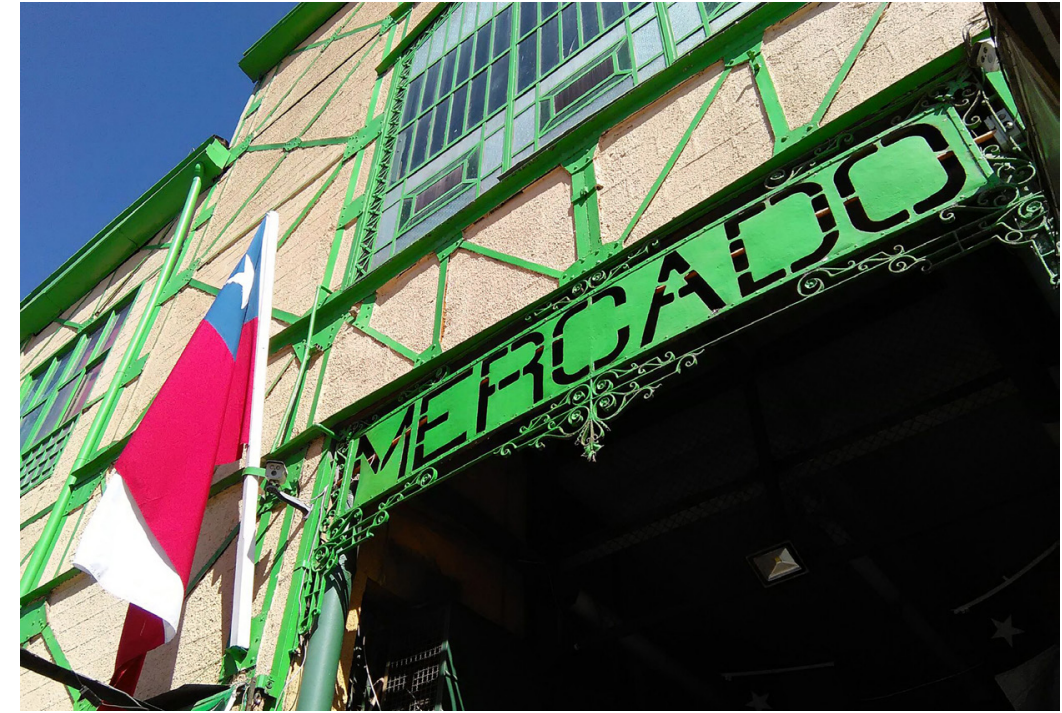

- Tipo de generación: existen al menos tres formas de crear letras. Primero, trazándolas a mano de manera formal o informal, mediante herramientas escriturales (caligrafía); segundo, dibujándolas para generar composiciones especiales (letragrafía, rotulación o lettering) y, tercero, mediante la generación y/o composición de sistemas alfabéticos (elección o diseño de tipografía). Estas tareas, para la letra en el entorno, por lo general, caían en manos de dibujantes técnicos, empleados del municipio y constructores, a diferencia de la letra para obras impresas, que era "propiedad" de los tipógrafos.

- Estilo: optamos por un modelo propio a partir de la clasificación adoptada por la Atypi, en 1962 (Vox-Atypi): con serif (clásicas más modernas serifadas, mecanas y toscanas); sin serif (o lineales grotescas, geométricas y humanistas); caligráficas (incisas, góticas, manuscritas, gráficas); y de fantasía o decorativas.

- Ubicación: observaremos letras asociadas a la arquitectura (fachada de edificios, bóvedas, letreros, marquesinas; a la calle (señalización, nomenclatura, monumentos, mobiliario urbano, espacios verdes); a los transportes (trolebuses, embarcaciones y ascensores) y a objetos de diversa índole.

- Material constitutivo: las letras se han fabricado en diferentes materiales. Podemos hallarlas realizadas en fundición de hierro, cemento, hormigón armado, madera, chapa, tinta, pintura, entre otros.

- Técnica de aplicación sobre el soporte: este tópico refiere a cómo se aplican los caracteres al soporte que los contiene. De esta forma, encontramos letras pintadas, caladas, moldeadas, enlozadas, fundidas, grabadas, fijadas, adheridas, impresas, estampadas, estarcidas, entre otros.

Por lo general, estas tareas también recaían en los proveedores, aunque algunas podían aplicarse in situ. Algunos se importaban prefabricados.

- Acabado superficial: es un punto que puede estar vinculado al material y/o a la técnica de aplicación.

- Soporte (materialidad): un complemento indispensable para estas letras es el soporte en donde se aplican. Estos no solo portan consigo a los caracteres, sino que brindan importantes datos para su datación, origen, características de fabricación, provisión, entre otros. Podemos encontrar soportes fabricados en varios materiales, como madera, metal, cemento, loza, vidrio, plástico, entre otros. 


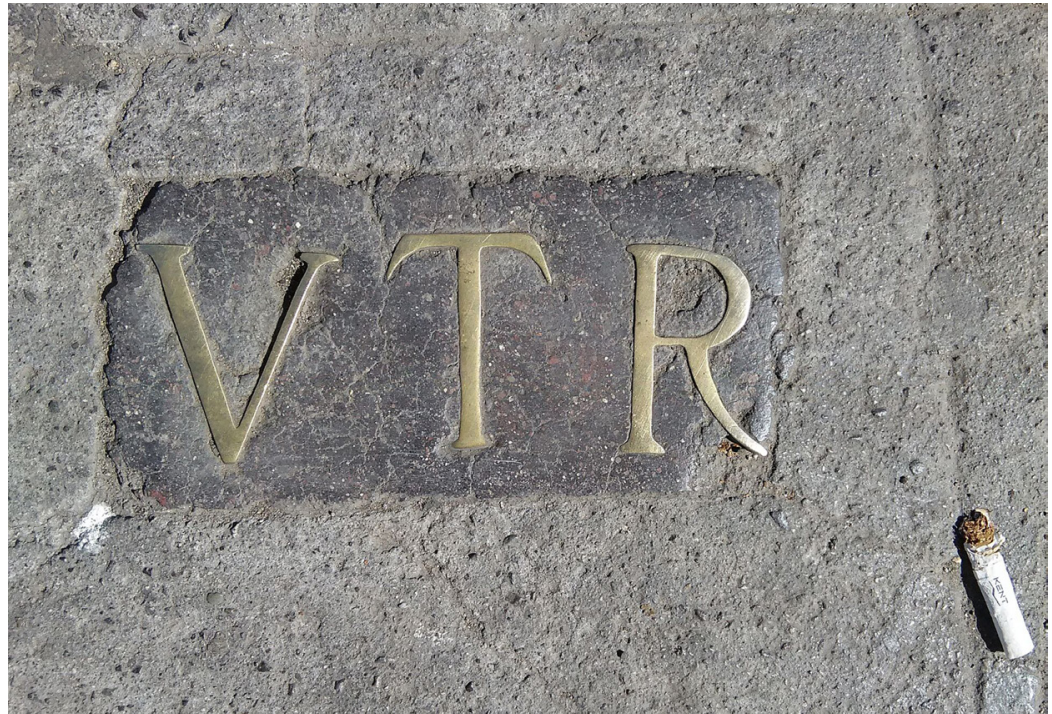

- Locación dentro de la planta urbana (zona, sector, dirección, entre otros).

- Año de creación o colocación (exacto o estimado).

- Autor y/o proveedor: en el caso que incluya la firma.

- Estado de conservación: observaremos el estado en el que se encuentran las letras con el fin de proponer acciones tendientes a su preservación.

- Documentos anexos: se tomarán al menos tres fotografías (plano general, primer plano y detalle). Además, se buscarán muestrarios tipográficos, planos, imágenes antiguas, legislación, bibliografía o cualquier otro material que permita asociar la letra con su historia y contexto de uso.

A partir del corpus reunido, clasificado y debidamente registrado, comienza la tarea de análisis ${ }^{4}$, contextualización y producción para la posterior difusión. Un plano importante para el análisis será determinar quiénes produjeron las letras, si se importaron especialmente o bien si se seleccionaron de modelos disponibles en casas especializadas -como es el caso de las empresas de letreros Hergo y Behrendsen, quienes se especializaron en la producción de carteles comerciales de acrílico-.

La elaboración de materiales de estudio, publicaciones, presentaciones y talleres valida la tarea investigativa y contribuye con nuevos aportes a la especialidad. De esta forma, además, podemos llegar hasta diferentes áreas de la cultura y el conocimiento, como al ámbito del diseño, y particularmente a los diseñadores de tipografías digitales (Ares, 2013). Podemos asegurar que en los países de Latinoamérica es creciente la preocupación de los diseñadores por el plano histórico de la tipografía.

Los diseñadores que conocen la historia de su propia disciplina pueden rescatar elementos para ampliar su universo cultural y visual, e incluso hacer nuevas interpretaciones o revivals a partir de las experiencias del pasado. El historiador de la tipografía de origen catalán Albert Corbeto (2012: s/p), señaló que los diseñadores:
Figura 6. Letras romana de bronce en una vereda de El Almendral. Fuente: elaboración propia.

4. La lectura relacional de los datos que se obtengan a partir del relevamiento permitirá responder las preguntas, y corroborar o desatender las hipótesis que nos planteamos al inicio del proyecto. 
Figura 7. Letras de palo seco geométricas en el Puerto. Fuente: elaboración propia.

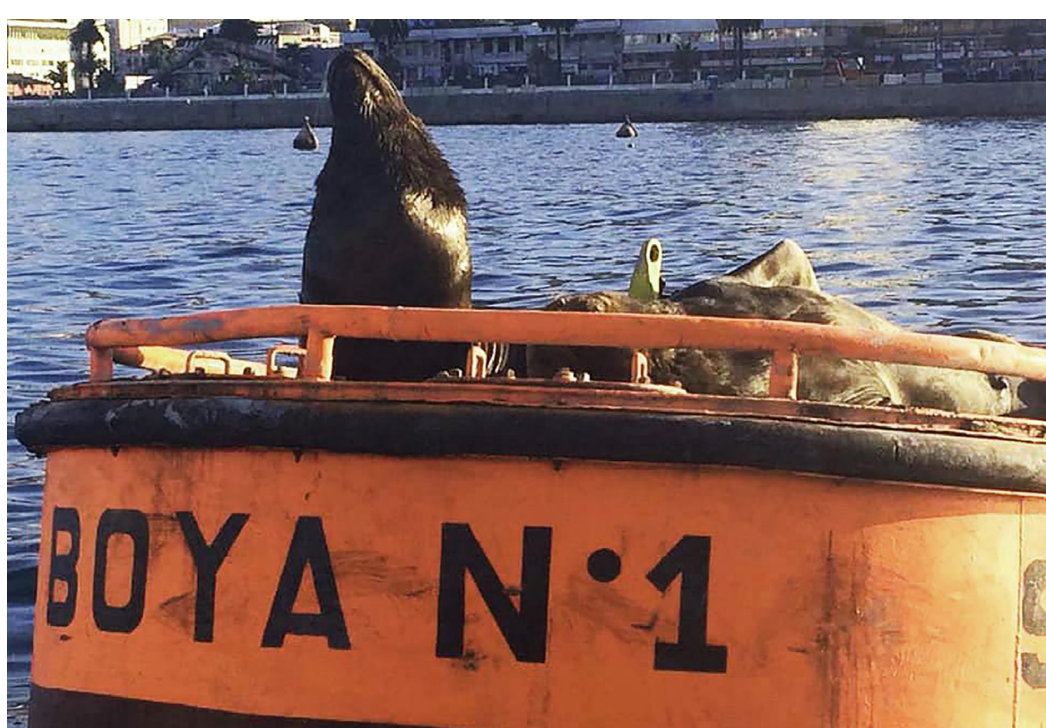

(...) además de disponer de las habilidades técnicas y creativas propias de su profesión, deberían interesarse por la historia, y no sólo de la más reciente (...) debemos mirar al pasado sin pretensiones de encontrar los modelos para un uso actual, pero sí para comprender el motivo de las decisiones que tomaron los antiguos tipógrafos (...) no me refiero a coartar la libertad creativa, ni mucho menos, pero sí pienso que es necesario saber cómo se hacían las cosas en el pasado para disponer de un bagaje con el que afrontar el diseño en las condiciones presentes.

\section{Resultados preliminares}

Desde 2016, se realizaron una serie de relevamientos en las diferentes áreas que permiten señalar algunas apreciaciones y distinguir algunas tendencias. Podemos decir que:

- El patrimonio tipográfico de las áreas patrimoniales de la ciudad es amplio, diverso, y en muchos casos requiere acciones que propendan a su restauración y conservación.

- Identificamos letras que cumplían -y aún cumplen- distintas funciones. Por ejemplo, identificar sitios y edificios, conmemorar acontecimientos u homenajear a individuos, informar sobre datos diversos, entre otros.

- En su gran mayoría, se optó por la rotulación mediante la selección de modelos de letras estandarizados, lo que acerca esta práctica a la tipografía como forma de generación, y no a la caligrafía o al dibujo (letragrafía o lettering). Es decir, que en estos casos se utilizaron letras premoldeadas, que se compusieron de acuerdo a cada necesidad de comunicación.

- Encontramos caracteres de diferentes estilos y su elección, al parecer, responde a las funciones de los mensajes que debían transmitir. Las letras con serif, por lo general están asociadas a la identificación de los edificios administrativos (salvo algunas excepciones, desde principios de siglo XX, más específicamente, a partir de la reconstrucción de la ciudad producto del devastador terremoto de 1906). Principalmente de molde, fabricadas en 


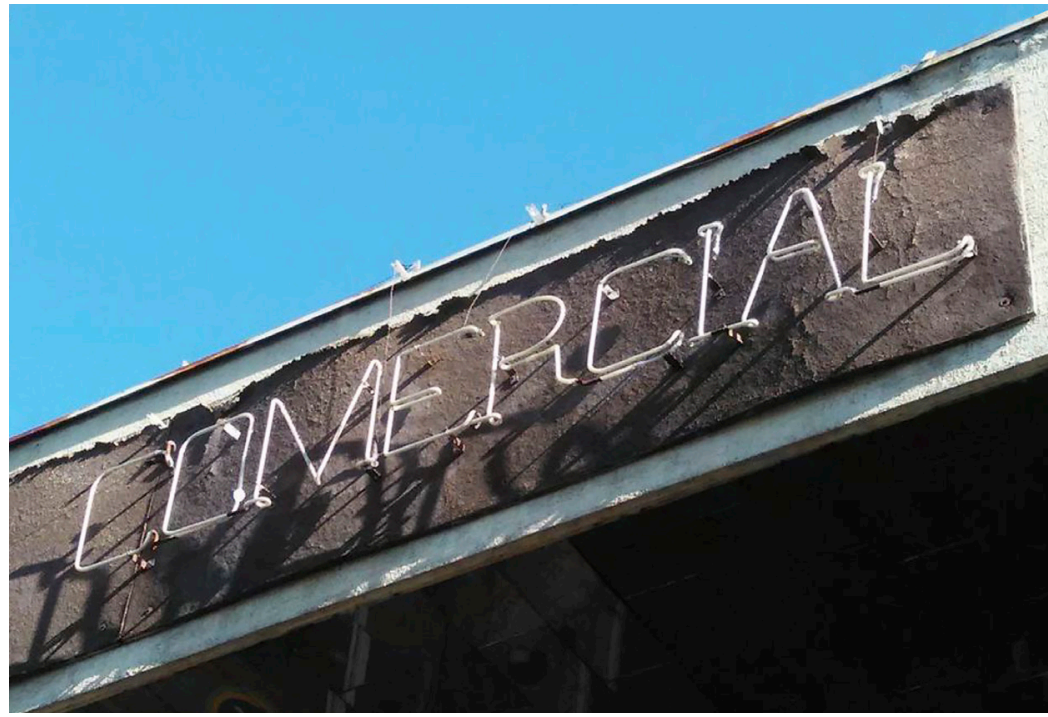

bronce o cemento; letras sin serif o lineales: fundamentalmente geométricas (por ejemplo, en monumentos y embarcaciones) y en algunos casos grotescas. De corte humanista en los trolebuses; caligráficas escritas informales y formales, menos frecuentes, pero generalmente vinculadas al rubro del comercio. Salvo las rotuladas de estilo gótico que fundamentalmente se asocian a la identificación institucional. Algunas decorativas, letragráficas, asociadas a la arquitectura y a letreros comerciales.

- Abundan los diferentes materiales constitutivos. Hay caracteres metálicos, de cemento, de madera, de acrílico, entre otros.

Como mencionamos anteriormente, un punto importante para nuestro proyecto es difundirlo a la opinión pública, tanto la metodología para abordar del relevamiento, como los resultados analíticos y las conclusiones que puedan surgir a partir de la investigación. Captar el interés del público y propender a transmitir la importancia de las letras dentro del funcionamiento urbano a través de la historia, también son formas de ponerlas en valor. Este es un valor que el público no suele darle, en medio de la vorágine de estímulos visuales que propone el entorno diario. Esto se llevará a cabo a través de presentaciones públicas ${ }^{5}$, artículos en revistas especializadas (como en este caso), publicaciones en formato de libro, y un catálogo web $^{6}$ que permitirá la búsqueda de los casos a través de diferentes filtros.

\section{Discusión}

En este punto nos gustaría repasar una serie de aspectos que se desprenden de la declaratoria patrimonial, y presentar de qué manera nuestro proyecto podría insertarse y hacer un aporte novedoso al paisaje cultural porteño. El Área Histórica de la Ciudad Puerto de Valparaíso fue inscrita en la Lista del Patrimonio Mundial UNESCO, en 2003, por ser un "testimonio excepcional de la fase temprana de globalización, a fines del siglo XIX, cuando se convirtió en el puerto comercial líder de las rutas marítimas de la costa del Pacífico de Sudamérica" (Mendes Zanchetti \& Calvo, 2014: s/p).

El Comité del Patrimonio Mundial alentó al Estado Parte (en este caso, Chile)
Figura 8. Caracteres de neón en el barrio El Almendral, zona comercial de Valparaíso. Fuente: elaboración propia.

5. El proyecto fue presentado por primera vez en julio de 2016, en Buenos Aires (Argentina), durante el Encuentro Latinoamericano de Diseño de la Universidad de Palermo. Además se presentó en la Universidad Iberoamericana (México); también en las Jornadas Internacionales de Diseño y Publicidad (Valparaíso, Chile); en el Seminario Internacional Ilustración \& Industrias Creativas (Santiago de Chile). Estas dos últimas organizadas por la Universidad Tecnológica de Chile INACAP (Sedes Valparaíso y Puente Alto); y finalmente, en el marco de la VII Bienal Latinoamericana Tipos Latinos (La Plata, Argentina).

6. Desde 2016 se encuentra en línea nuestro sitio web. Autogestionable y de diseño responsivo, tiene la doble función de servir para difundir el trabajo y como inventario patrimonial. El desarrollo está a cargo del grupo de diseño porteño Escaparate, con la coordinación del docente Rubén Jordán. Puede consultarse en http://www. valpociudadeletras.com/ 
a "proseguir los esfuerzos para realizar un inventario y proteger la infraestructura relativa a las funciones históricas de la zona del puerto y de los sistemas de transporte; elaborar planes de gestión de conservación en toda el área del puerto marítimo; y solicitó aclarar con mayor precisión las normativas y directrices con respecto a áreas adyacentes a las zonas protegidas, por ejemplo, la Plaza de la Intendencia, el Cementerio y la Plaza San Francisco" (Mendes Zanchetti \& Calvo, 2014: s/p).

El ente supervisor de los bienes y parte de su zona de amortiguamiento, en su condición de Monumento Nacional (1971), es el Consejo de Monumentos Nacionales de Chile. Mientras que el Ministerio de Vivienda y Urbanismo se encarga de los bienes mismos y su zona de amortiguamiento comprendida en un área más amplia y declarada como Zona de Conservación Histórica. La Municipalidad de Valparaíso es la autoridad que responde por la gestión y administración del bien, y por último se encuentra una de sus dependencias, la Dirección de Gestión Patrimonial, la cual está a cargo de coordinar los proyectos que se implementen en el área (Plan de Manejo).

En 2013, una misión de asesoramiento del CPM visitó Valparaíso para evaluar el estado de conservación, la gestión y la protección en general, los proyectos en marcha y los previstos, para el Sitio de Patrimonio Mundial. A continuación, se presentan algunas de las conclusiones y recomendaciones que fueron incluidas en su informe:

- La misión valoró el gran esfuerzo y el buen desempeño del CMN y de la conservación del sitio de patrimonio mundial y de otros bienes patrimoniales en la ciudad.

- Se identificaron una serie de problemas que podrían agruparse en tres temas. Primero, la necesidad de que las instituciones a cargo de los bienes puedan adoptar un enfoque más amplio con respecto a la interpretación y la gestión de los atributos del sitio de patrimonio mundial. Segundo, el proceso de negociación entre las partes involucradas en el desarrollo y el patrimonio de la ciudad. Tercero, las intervenciones de conservación en el sitio de patrimonio mundial. A pesar de la complejidad y la buena calidad técnica del Plan de Manejo, este plan carece de ciertas características relativas a la interpretación del Valor Universal Excepcional del sitio de patrimonio mundial como un paisaje cultural y a la participación de los principales actores de la ciudad. El Plan no abarca las importantes relaciones culturales que existen entre el área protegida y la ciudad, en el cual se incluye al puerto.

- Se ha comprobado la falta de estructura para una gestión integral por parte de los diferentes organismos, que, si bien han podido definir mecanismos de trabajo conjunto, esto parecieran no ser suficientes para tomar decisiones integrales y coordinadas.

- Consideraron que sería importante que el Plan establezca un espacio institucional para que otros actores sociales participen e inviertan en servicios culturales, educativos y turísticos.

De estos puntos se desprenden algunos aspectos en los cuales Valpo. Ciudad de Letras podría hacer algunos aportes.

A nuestro criterio, la clave está en tener un enfoque más amplio, para entender al Bien como paisaje cultural, y establecer relaciones culturales entre la ciudad, su historia, sus actores y el plano de la letra. 

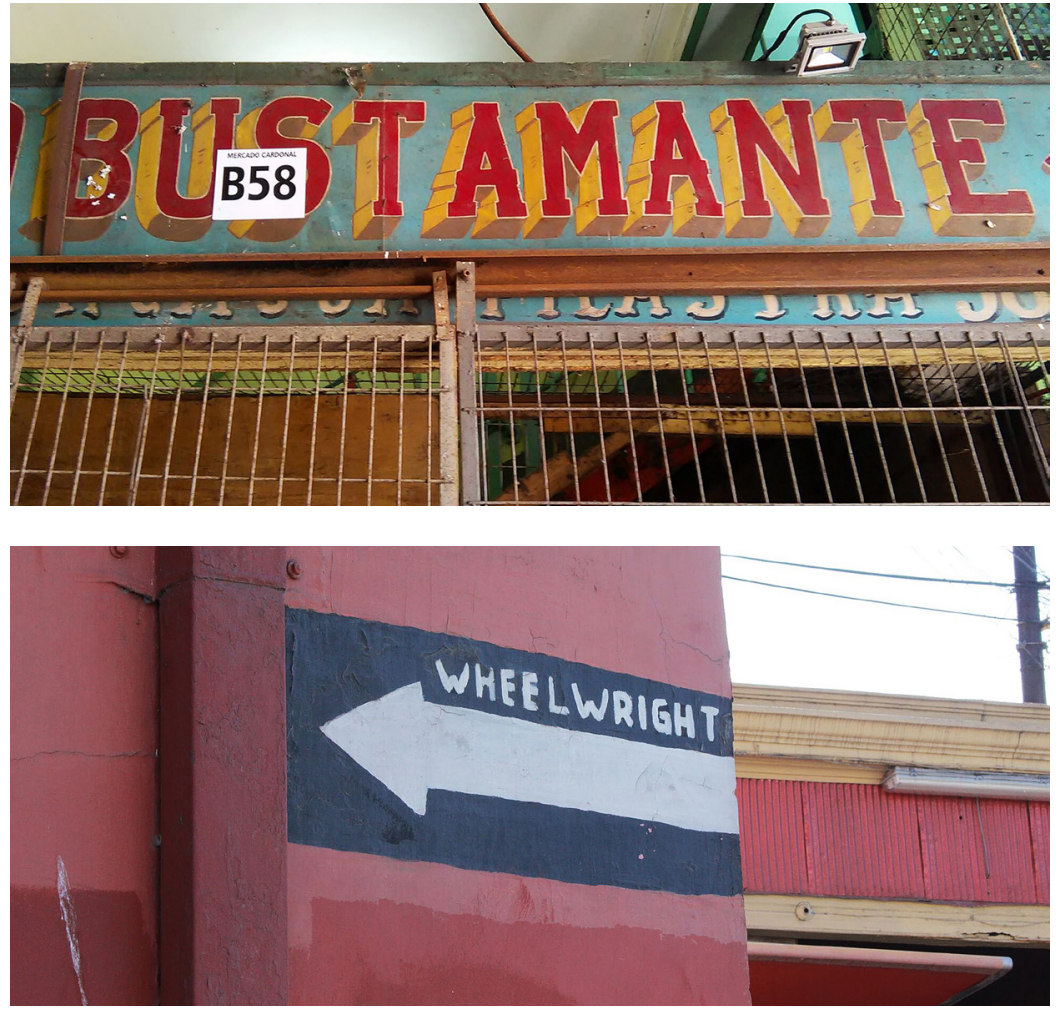

El proyecto consideró importante sumar a las áreas protegidas, el barrio El Almendral, puesto que allí se concentra la mayor cantidad de comercios, y con ellos letreros. Otra incorporación es el sistema de transporte, horizontal y vertical (ascensores).

En 2016, se tuvo la oportunidad de visitar y presentar nuestro trabajo en la Dirección de Gestión Patrimonial. Si bien se mostraron interesados en la propuesta -sobre todo en el enfoque temático-, aún no se ha formalizado el vínculo para un trabajo conjunto.

\section{Conclusiones}

Cada letra esconde una historia, al descubrirla aprendemos un poco más sobre la comunidad que la produjo. Esto puede brindarnos pistas sobre sus orígenes, sobre quién y de qué manera la generó, sobre su producción y su circulación, lo que contribuiría a sumar un plano novedoso sobre el patrimonio de la ciudad entendido como paisaje cultural.

Estos aspectos, además podrían servir de base teórica para nuevas interpretaciones de diseño tipográfico, como un rescate de la identidad porteña para proyectarse hacia otras realidades.

Señalar cada caso de rotulación, y establecer una suerte de diagnóstico sobre su estado de deterioro, podría contribuir a su restauración y preservación (siempre que puedan articularse una serie de acciones específicas junto con especialistas, y por supuesto, con las autoridades correspondientes). Entendemos que este es un trabajo de largo aliento, pero ya estamos en marcha en pro de estudiar, recuperar y poner en valor el legado de la letra urbana de Valparaíso.
Figura 9. Letragrafía pintada en un puesto del Mercado El Cardonal. Fuente: elaboración propia. Figura 10. Letragrafía para la nomenclatura urbana. Fuente: elaboración propia. 


\section{Referencias bibliográficas}

Ares, F. E. (2013). El anclaje histórico, en Lamónaca V. (comp.), Tipografía Latinoamericana. \{Un panorama actualy futuro\}. Buenos Aires, Argentina: Wolkowicz Editores, 84.

Ares, F. E. \& Osores O. (2015) Station to station: the graphic heritage of the Argentinian railways, Ultrabold. The journal of St Bride Library, 17. Londres: St Bride Fundation, 12-26.

Baines, P. \& Dixon, C. (2004). Señales. Rotulación en el entorno [1 $1^{\text {a }}$. ed. en español]. Barcelona: Blume, 2004.

Bartram, A. (1975). Lettering in architecture. Londres: Lund Humphries.

Corbeto, A. (2012, enero). La pasión por las letras y su historia. Entrevista. Madrid, España: Unos tipos duros. Consultada el 12 de agosto de 2012 en http://www. unostiposduros.com/albert-corbeto-la-pasion-porlas-letras-y-su-historia/).

Farias, P. L., Silva Gouveia, A. P., Pereira, A. L. T., Gallo, H. \& Gatto, P. S. (2008). Técnicas de mapeamento aplicadas a o estudo da epigrafia arquitetônica paulistana. InfoDesign. Revista Brasileira de Design da Informação, 5. San Pablo: Sociedade Brasileira de Design da Informação.

Garone Gravier, M. (2004). La historia en la enseñanza y aprendizaje de la tipografía, La Puerta, 1, La Plata: Facultad de Bellas Artes, Universidad Nacional de La Plata, 42-51.

González Díez, L. \& Tabuenca Bengoa, M. (2015), Madrid Tipográfico. Un recorrido ilustrativo por la rotulación de la Gran Vía, Arte y Ciudad. Revista de Investigación, 7 , Madrid, España: Grupo de Investigación Arte, Arquitectura y Comunicación en la Ciudad Contemporánea, Universidad Complutense de Madrid, 27-46.

González, S. H. (2014, mayo). Memoria de la escritura y la tipografía en la arquitectura y la ciudad. Ponencia presentada en el Coloquio Argentino de Patrimonio e Historia de la Tipografía, Buenos Aires, Argentina.

Gray, N. (1960). Lettering on buildings. New York: Reinhold. Hernández Falagán, D. (2014). Tipografías arquitectónicas, Grafica, 3 (14), 19-29, Barcelona: Universitat Autònoma de Barcelona.
Huerta, R. (2013). Docentes paseando por las letras de la ciudad, Arteterapia: Papeles de arteterapia y educación artística para la inclusión social, Vol. 8, Madrid, España: Universidad Complutense de Madrid, 123-136.

Huerta, R. (2017). Investigar sobre tipografía urbana desde la Educación Artística. La ciudad de Cuenca (Ecuador) revisitada por sus docentes, Tsantsa. Revista de Investigaciones Artísticas, Cuenca, Ecuador: Facultad de Artes, Universidad de Cuenca, 5-22.

Mendes Zanchetti, S. \& Calvo, L. M. (2014, enero). Informe Unesco sobre Patrimonio de Valparaíso. Informe de Misión de Asesoramiento para el Sitio de Patrimonio Mundial Área Histórica de Ciudad-Puerto de Valparaíso. Informe remitido al Estado Parte por el Director del Centro de Patrimonio Mundial de la UNESCO.Santiago, Chile: Consejo de Monumentos Nacionales. Consultada el 10 de marzo de 2016 en http://www. valparaisopatrimonio.cl/index.php/noticias/173-informe-unesco-sobre-patrimonio-de-valparaiso

Salomon, C. A. X., Silva Gouveia, A. P. \& Farias, P. L. (2009) Fichas de pesquisa de campo para estudo da tipografia nominativa na arquitetura carioca. InfoDesign. Revista Brasileira de Design da Informação, 6, San Pablo, Brasil: Sociedade Brasileira de Design da Informação.

Sánchez, A. (2014, mayo). Tipografía edilicia urbana. Imaginarios, materialidades e identidad visual en la Buenos Aires moderna. Ponencia presentada en el Coloquio Argentino de Patrimonio e Historia de la Tipografía, Buenos Aires, Argentina.

Silva Gouveia, A. P., Pereira, A. L. T., Farias, P. L. \& Barreiros, G. G. (2007). Paisagens tipográficas - lendo as letras nas cidades, InfoDesign. Revista Brasileira de Design da Informação, 4, San Pablo, Brasil: Sociedade Brasileira de Design da Informação.

Silva Gouveia, A. P., Farias, P. L. y Gatto, P. S. (2009). Letters and cities: reading the urban environment with the help of perception theories, Visual Communication, 3, Vol. 8, New York, EE.UU.: Sage Publications, 333-342. 